\title{
CHAPTER 9
}

\section{ORTADOĞU'DA TARİHSEL GELIŞMELERIN GÖLGESINDE ŞEHIRLER VE RESSAMLAR}

\section{PAINTERS AND CITIES IN THE SHADOWS OF HISTORICAL ISSUES IN THE MIDDLE EAST}

\author{
Ahmet Emre ATEŞ ${ }^{1}$ \\ 'Doç. Dr., İstanbul Üniversitesi, İktisat Fakültesi, Siyaset Bilimi ve Uluslararası İlişkiler Bölümü, \\ İstanbul, Türkiye \\ e-mail: aeates@istanbul.edu.tr
}

DOI: $10.26650 / \mathrm{BS} / \mathrm{AA} 23.2021 .001-2.09$

ÖZ

Ortadoğu'nun önemini ve tarihini politik anlamda anlayabilmek için günümüzde sadece uluslararası ilişkiler, diplomasi ve/veya ekonomi üzerinden anlamak yetersizdir. Bu bağlamda edebiyat, felsefe, sanat gibi farklı disiplinler üzerinden Ortadoğu'yu anlamak, bu bölgede yaşanan politik gelişmelerin neden ve sonuçlarını daha iyi kavramayı sağlar. Ortadoğulu ressamların sayısı yirminci yüzyılda modern ve sonrası akımların gelişmesiyle giderek artmıştır. Ortadoğulu ressamların yaşadıkları şehirlerle ilgili görsel eserler meydana getirmelerine yirminci yüzyılda sıklıkla karşılaşılır. Bu noktada amacımız, Soğuk Savaş ve sonrası Ortadoğu'da çağdaş/güncel sanatın gelişimini değerlendirmektir. Evler, çarşılar, göç, savaş, kadın-erkek ilişkileri gibi pek çok sosyo-politik konunun yorumlandı̆̆ şehir resimlerinde, Ortadoğu'nun görece bir siyasi tarihi betimlenmektedir. Bir başka anlatımla, performatif veya kavramsal sanat eserlerinin yer aldığı çeşitli video ve enstalasyon çalışmalarıyla çeşitlenen şehir resimleri, Ortadoğu'yu ortaya koymaktadır.

Raghed Ayad, Marwan Rechmaori, Diana al Hadid, Ahmed Alsoudani, Nadia Ayari, Shadi Ghadirian gibi çoğunlukla Ortadoğu'da doğmuş olsun veya olmasın, Ortadoğu kökenli olan sanatçıların, kendi ülkelerine ve şehirlerine ait tespit ve yorumlarını içeren çağdaş eserleri, günümüzde başta Amerika ve Avrupa olmak üzere birçok kıtada sergilenmektedir. Söz konusu eserlerde, bölgenin kültürel özelliklerine değinilirken, uluslararası ilişkilerin ve gerilimlerin kültür politikaları ve/veya kültür propagandası üzerinden yarattığı söylemlerin nasıl savaş unsuru haline getirdiği tartışılmaktadır. Türkiye'deyse Ortadoğu üzerine yapılan tartışmalar düşünsel temelli olup, 
görsel sanatlar bağlamında yapılan çalışmalar kısmen ve/veya tamamen sınırlı kalmaktadır. $\mathrm{Bu}$ bağlamda çalışmanın katkısı, Bağdat, Kahire, Beyrut gibi Ortadoğu şehirlerinin söz konusu çağdaş sanatçılar tarafından nasıl ele alınıp, ülke tarihlerini nasıl farklı teknik ve yorumlarla yansıtıldığını incelemektir.

Anahtar Kelimeler: Ortadoğu, şehirler, ressamlar, çağdaş sanat, şiddet

\section{ABSTRACT}

The Middle East is always considered as being conflictual. It is now impossible to understand the dynamics of the Middle East only througheconomics or international relations. Therefore, the current tendencies to understand the Middle East must focus on different disciplines like literature, philosophy and art in order to solve political conflicts. Accordingly, our aim is to analyse the development of contemporary art in the aftermaths of the Cold War. It can be argued that most of the artworks related to tMiddle Eastern cities deal with the dynamics of political tensions of the region. In other words, within the framework of conceptual art or performance ones, the actual conjuncture of the Middle East is depicted throughout the contemporary artists of the region who are interested in the city-scapes.

Contemporary masterpieces of the Middle Eastern artists like Mona Hatoum, Oraib Toukan, Alaa Awaad, Ebtisam Abdulaziz, Marwan Rechmaori, Diana al Hadid, Ahmed Alsoudani and Walid Raad are exhibited with the concern of their own homelands and cities. In their masterpieces, the main focus is that the international relations concerning the Middle East transform any cultural politics into a political one and thus strengthen the boundaries more and more. The ignorance of the cultural assets of the Middle East indiscussions prevents further interpretations of the region. This is why, the main contribution of this essay is to illustrate the artistic depiction of cities like Beirut, Bagdad, Cairo in order to understand the contemporary and cultural dynamics of the Middle East.

Keywords: Middle east, cities, painters, contemporary art, violence

\section{EXTENDED ABSTRACT}

From Sykes-Picot to Camp David, the Middle East is always seen as the subject and the object of a diplomatic affair. However, the Middle East and its political issues are not only a matter of international relations. In order to obtain a solution covering the problems existing within the Middle East, one must refer to some different academic fields. Not only international relations, neither economics, nor sociology may absolutely explain or solve the tensions in this problematic region. Instead, mundane disciplines like literature, philosophy, architecture and art render more efficient alternatives in order to gain a deep understanding ofwhat is going on in the Middle East.

Such an attempt to gather new disciplinary perspectives is also inevitable to avoid a pejorative understanding of orientalism which becomes a political weapon to produce new weapons. In this sense, the more the pejorative an understanding of orientalism is revitalized, 
the more the political conflicts are deepened. In other words, like the assumption which regards the peace treaties of Versailles as" a peace to end all peace", the pejorative concentration over orientalism may be considered as "a weapon to produce all weapons."

It can be argued that the main target of this inquiry is to encourage an understanding of the Middle East with descriptions of the regional cities in the eyes of the painting artists. Throughout the research, first of all, the question of orientalism must be discussed. Secondly, the city formation of the Middle East should be deprived form such a pejorative understanding of orientalism. Thirdly, the Middle Eastern artists and their masterpieces on fhe regional cities may be analyzed. Finally, it can be argued that each city has its own soul/geist as a response to all political problems shadowing the Middle East and that anything except this soul is a part of an artificial calculation.

To begin with, one must refer to Oleg Grabar's arguments. According to him, it is not surprising to combine both the neoplasticism of Piet Mondrian and the suprematism of Kazimir Malevich with the pure geometrical ideals of Islamic thought. Therefore, there is a correlation between any old city of the Middle East and the artistic soul of the twentieth century. Therefore, it can be argued that modernity and tradition coexist in the region. Yet, the political tension of the decades makes the regional citiesand their native's rights more dramatic than Henri Lefebvre's understanding of "le droit à la ville", this is to say, the "right to city".

Starting with the Caire School of Fine Arts which was established in 1908, the Middle East has met with the art of painting since the beginning of the twentieth century. With the initiatives of Mohammed Naji, Raghed Ayad, and Mahmoud Mokhtar, the artistic milieu shows interestin the cities in the Middle East. Almost all of the painters of the Middle East have in mind the cultural diversity of their cities together with the unfortunate situation with which these cities have been challenged since the belligerent times from Cairo to Lebanon, from Baghdad to Damascus.

The main topic in the iconology of the artpieces deals with the shape of borders influencing the features of Middle Eastern cities. In this case, Mona Hatoum contributes with the examples of conceptual art. Also, Oraib Toukan illustrates the citizen's conduct in urban life via performative art. While Alaa Awaad tries to recall Egyptian civilization in the city walls, both Walid Raad and Marwan Rechmaouri use this similar approach within the street's installations. In addition to the legacy of the cities, contemporary artists like Diana al-Hadid and Ebtisam Abdulaziz demonstrate the interaction between the individual and the city in the shadows of the politically marginalized Middle East region. 
By doing so, each painter presents his artistic piece with a philosophical approach. One the one hand, Alaa Awaad codifies the historical arguments of Fernand Braudel with the regional cities. On the other hand, Marwan Rechmaouri is inspired by Henri Lefebvre in the sense of the right to the city. Moreover, Ebtisam Abdulaziz gives importance to Jurgen Habermas famous Notion of "public space" in a geography turmoiled by ethnic conflicts. By the same token, Walid Raad figures out the simulacrums of Jean Baudrillard in his understanding of both the past and the present concerning Middle Eastern cities. Finally, Diana al-Hadid resumes the existentialist asset of these regional cities.

To sum up, the majority of contemporary painters who are related to Middle East, contribute to the identity of their own cities by sharing their visual artistic approaches. In order to distinguish the truth with the reality so far as these regional cities are concerned, the examples of contemporary art pieces are elementary. Such different tentatives must be encouraged in order to rediscover the past of the cities which need to rebuild their future, as a response to their present and obsolete conditions under conflicts and warfare. 


\section{Giriş}

Ortadoğu'da yaşananları anlayabilmek için salt uluslararası ilişkiler veya tarihe bakmanın günümüzde yetersiz kaldığı iddia edilebilir. Felsefe, edebiyat, sosyoloji, güzel sanatlar “Ortadoğu” kimliğini diğer disiplinlerden görece daha fazla başvuru noktası olmalıdır. Gerek dünya, gerekse Türkiye kamuoyunda Ortadoğu'nun anlaşılması gün geçtikçe daha da önemli olmaktadır. Bu çalışmanın amacı Ortadoğu’nun merkezi şehirlerini çağdaş ve güncel sanat üzerinden yorumlamaktır.

Öncelikle Ortadoğu şehirlerinin dilini ve ressamlarının iç dünyasını anlayabilmenin yolu birinci sırada kent sosyolojisi ve tarihi üzerine konuşmakla başlamalıdır. İkinci olarak, bölgeyi ilgilendiren sözde oryantalist çarpıtmalarla mücadele etmek gerekir. Üçüncü olarak şehirlerin dilini, Ortadoğulu sanatçıların gözünden analiz etmek temel konumuz olacaktır.

\section{1. Şehirler ve Oryantalizm}

Ortadoğu'da tarihsel gelişmelerin gölgesinde şehirler ve ressamlar konusunun amacı aslında bölgedeki çağdaş sanatçıların kendi ülkelerindeki şehrin dilini nasıl betimlediklerini ortaya koyabilmektir. Bu bağlamda, ikinci kısımda ele alacağımız Ortadoğulu çağdaş sanatçılara ve şehir temalı eserlerine değinmeden önce, ilk olarak şehir ve kentin ne olduğunu tartışmak ve Ortadoğu' daki iz düşümüne oryantalizm tuzağına düşmeden bakabilmek gerekir.

“Şehir Hakkı" adlı kitabında Henri Lefebvre, bireylerin ve toplumların üzerindeki şehir ile kent baskısını derinlikli biçimde anlatmaktadır. Lefebvre, çeşitli toplum ve sınıflar açısından, şehir ve mekânın kent adıyla ortaya çıkan yeni gerçeklikte ötürü yok olmasını inceler. Buna karşı1ık, şehir hakkı veya kentsel yaşam hakkına referansla, yersiz-yurtsuzlaşmayla mücadele etmeye çalışır. Şehirlerin, şehir hayatı, kentsellik veya kent zamanı gibi kullanım değeri ile alınıp satılan mekânlar, ürünlerin, malların, yerlerin ve işaretlerin tüketimi gibi mübadele değeri arasındaki karşıtlık söz konusu mücadelenin bir parçasıdır. Bu mübadele değerinin kullanım değerinin önüne geçmesi ve bu noktada kar sağlayamayan sınıfların söz hakkını yitirmesi, kaçınılmaz bir gerçek olmaktadır (Lefebvre, 1972, s. 36).

Tarihsel açıdan politik şehir ticari şehre, ticari şehir sanayi şehrine, sanayi şehri ise kritik şehre dönüşür (Lefebvre, 1972, s. 79). Antik Yunan'dan Orta Çağ Avrupa'sına, sonrasında modernite ve sanayi çağının etkileri şehirleri planlaya dursun yirminci yüzyılda kitle iletişim araçlarının çoğalması ve gündelik hayatın bölünmesi şehir ve kent yaşamını içinden çıkılmaz bir döngüye sürüklemektedir. Böylelikle, silikleşen komşuluklar ve ufalanan mahalleler, özne ile mekân arasındaki ilişkiyi yok etmeye başlıyor. Bu değişimlere rağmen, Lefebvre'in 
ifadesiyle "dünya savaşlarının, büyük katliamlara eşlik eden ciddi nüfus artışları, ekonomik büyüme ve rekabetin sert gerekliliği karşısında" (Lefebvre, 1972, s. 109) şehir hakkını veya bir başka anlatımla kentsel yaşam hakkını formüle etmek gerekiyor.

Yenilenmiş, kent yaşamına dâhil olan şehir hakkı, Lefebvre'e göre, merkezden çeperlere sürülmenin veya merkezde yabancılaşmanın önüne geçmek için "faydalanma hakkına" vurgu yapar. Fakat Batı şehirleri veya kentleri için geçerli kabul edilebilecek bu durum ve çözüm önerileri, Ortadoğu şehirleri açısından muğlâk kalmaktadır. Bölgesel savaşların ve etnik çatışmaların gerek ülkesel gerekse kentsel sınırları zorladığı bir coğrafyada eksikler ve çözümler üzerine etraflıca düşünmek gerekir. Savaşın ve barışın mutlak anlamda kullanılamayacağı bir düzlemde sınır tanımayan ve "yönsüzleşmiş" bir savaş hali (Kardeş, 2019, s.175) özellikle Ortadoğu'da egemen hale gelmiştir. Bu bağlamda, Batı-merkezli şehir ve kent algısının en az savaşlar kadar tehlikeli bir biçimde Ortadoğu şehirleri üzerine yarattığ yanlış bilinçlenmeyi de ele almak gerekir.

Ortadoğu şehirlerini ve ressamlarını anlayabilmenin yolu ve bu yolla kent sosyolojisi ve tarihi üzerine konuşabilmek için sözde oryantalist çarpıtmalarla mücadele etmek gerekir. Örnek olarak, tırnak içinde "Arapların göçebe, bir çöl halkı” olduğuna dair söylem ne yedinci yüzyılda ne de günümüzde doğrudur. Orta Çă̆' da yaşamış Tunuslu yazar İbni Haldun'un "Mukaddime"de Kuzey Afrika göçebe toplumları için vardığı sonuçları Arap dünyasında bir bütün olarak kabul etmek yanlıştır. Fred Halliday’e göre, Arap yarımadasında yaşayan çoğu insan Yemen ve Umman'da olduğu gibi ya tarım işçisidir ya da Manama, Dubai, Mukalla, Aden, Muskat, Cidde gibi liman şehri sakinleridir. Dolayısıyla, "Çöl” ifadesi Arap yarımadasının ancak dörtte biri için geçerli olabilir (Halliday, 2008, s. 21-22).

Hiç kuşkusuz, Batı dünyasının Doğu karşısındaki bu tarz önyargılarını ortaya çıkartan kitapların en etkilisi Edward Said'in Şarkiyatçılık (1978) adlı eseridir. Said'in çıkış noktası olarak esinlendiği Claude Lévi-Strauss'un değimiyle Batı düşüncesindeki "Orient” ile “Occident" arasında kurulan ikili karşıtlık, "onlar" ve "biz” ayrımını esas almaktadır (Burke, 2006, s. 66). Said'e göre, 18. Yüzyıl sonlarından itibaren oryantalizm açık veya kapalı şekilde "Doğu"ya egemen olmanın bir planıdır. Bu plan, onu yeniden şekillendirmenin ve üzerinde bir üstünlük kurmanın stratejik bir yolu olmuştur.

Said, "Doğu"nun kendi değimiyle oryantalize edilmesini, "Modern şarkiyatçılığın yükselişiyle oryantalist kurumların büyümesi (keşifler, çeviri fonları, akademik departmanlar) Ortadoğu'da güçlü ticari, siyasi ve askeri kolonyal mevcudiyetin gittikçe artışı arasındaki ilişkiyle" (Said, 2016, s. 49) özetlemektedir. Said, örnek olarak, Renan’ın bir kitabını ele alıp, 
kitap üzerinden Gobineau'nun, Fransız diplomatik servisinin ve karşılaştırmalı anatominin sömürücü çıkarlar ağını inceleyebilmektedir.

“Doğu”nun metinsel olarak yeniden inşa edildiği Şarkiyatçılık metinsel bir söyleme bürünmektedir. Doğulu söz konusu olduğunda, Said açısından Şarkiyatçılık, "Doğuluyu metin olarak Batıya teslim eden, Batı tarafından işgal edilip kaynaklarının sağılmasına ve insani açıdan mahvedilmesine imkân sağlayan operasyonel ve etkin bir bilgi ve iktidardır" (Said, 2016, s. 50). Söz konusu hegemonik güç, Batıyı, Doğunun karşısında bir özne yapmaktadır. Doğuysa bu öznenin, nesnesi konumuna hapsolur.

“Oryantal” olanı hiç de uygun olmayan şekilde oksidental olanla karşılaştırma eğiliminin kaynakları da sorunludur. Said'e göre modern Araplarla ilgili olarak Batı'daki hiçbir kitapta, Arap yazısının incelenmesi bulunamayacağı gibi, bugünkü Ortadoğu uzmanlarının çoğu, Arap toplumu hakkında 19. Yüzyıl oryantalistlerinden devralınan bir takım basma kalıplara referans vermektedirler. Bununla birlikte, “Araplar ya da Müslümanlar tarafından yapılan araştırmalar asla zikredilmez, ne de İ́slam'ın politik bir din olduğu ve İslam ile İslami yaşam arasında bir fark olmadığı şeklindeki eski klişelerin (...) yanlışlaşıp yanlışlanmadığına bakılmaz.” (Said, 2016, s. 348)

Karşı çıkılan söz konusu Avrupa merkezci bakış, batıyı yenilikçi, akılcı, bilimsel, disiplinli, işlevsel, özgür ve medeni olarak kabul etmektedir. Avrupa merkezci bakış, doğu algısını taklitçi, akılcı olmayan, batıl ve geleneklere bağlı, tembel, işlevsiz, esir ve barbar olarak inşa etmektedir. Jack Goody’nin “tarih hırsızlığı” ile nitelendirdiği bu durum, bir bakıma tarihin Batı tarafından ele geçirilmişliğini anlatmaktadır. Böylece insanlığın geçmişine dair hümanizma, demokrasi, ticaret, sanat, vb. gelişimlerin özellikle Batı Avrupa ölçeğinde olup bitenlerle kavramsallaştırılıp, dünyanın geri kalanına sunulmaktadır (Goody, 2014, s. 1).

Oryantalist söylemin iddialarının aksine John Hobson "Batı Medeniyetinin Doğulu Kaynakları” (2004) adlı eserinde üç önemli tezi pekiştirir. İlki, Batı’nın yükselişini sağlayan şeyin akılcı huzursuzluk değil, ırkçı huzursuzluk olduğudur. İkincisi, küresel yapı ve kimlik arasındaki bağ göz önüne alındığında, Edward Said'in belirttiği gibi “Doğu'nun, Avrupa materyal uygarlık ve kültürünün ayrılmaz bir parçası olduğudur”. Üçüncüsü, "Doğu kaynaklarının yağmalanmadan ve sömürülmeden Batı'nın kendi iç gücünün yüceliğinin” ortaya çıkamayacağıdır (Hobson, 2008, s.300).

Avrupa Rönesans'ında önemli üretim, ticaret, entelektüel ve sanat hareketlerinin meydana geldiği tartışılmaz. Fakat Jack Goody’nin de vurguladığı üzere Avrasya'daki yazılı kültürlerde de farklı canlanma dönemleri olduğu aşikârdır. 16. yüzyıl genişlemesinden ve her şeyden çok 
19. Yüzyıl sanayileşmesi aracılığıyla Avrupa'nın dünya tarihi üzerindeki hâkimiyetine karşı en önemli yanlışlama gerçek anlamda bronz çağını bir "kent devrimi” olarak betimleyen Gordon Childe'ın eserleriyle başlar. Modern dünyanın tarihinde kritik nokta, Gordon Childe'ın prehistoryacı bakış açısıyla, Avrupa ve Asya'ya yayılmış olan bronz çağının uygarlıklarının genel birliğini vurgulamak veya vurgulayamamaktır (Childe, 2006, s. 34-35). Söz konusu birlik, "kent devrimi”"nin bir ürünüdür (Childe, 2006, s. 105).

Başlangıçta belirtildiği gibi sözde oryantalist iddialar ve jeopolitik savaşların ağırlığı Ortadoğu şehirleri üzerinde bir çıkmaz yaratmaktadır. Bu çıkmaz, Henri Lefebvre’in batı şehirleri için tespit ettiği durumun ve hakların Ortadoğu'da uygulanmasını zorlaştırmaktadır. Öte yandan, varlığından haberdar olmadığımız ve bu nedenle sosyo-kültürel özelliklerini öğrenmekte zorluk çektiğimiz günümüz Ortadoğu toplumlarını anlamanın, belki de en önemli yolu Ortadoğu'daki çağdaş sanatın kendi “şehirlerinin dilini” nasıl betimlediğini göstermektir.

\section{Ortadoğu'da Çağdaş Sanat ve Şehirler}

Ortadoğu şehirlerini çağdaş/güncel sanat eserleri aracılığıyla gözlemlemek mümkün müdür? Bu soruyu cevaplamak için Oleg Grabar'ın çağdaş sanatlarda klasik Doğu ile modern Batı arasında eşit ve benzer kavramsal önermelere nasıl kapı araladığına değinmek gerekir. Grabar'a göre, İslam sanatında tastir ve tevrik süslemelerindeki aritmetik ve geometrik düşüncenin bir benzeri, neoplastisizmin öncülerinden olan Piet Mondrian'da ve süprematizmin önemli isimlerinden olan Kazimir Maleviç’te gözlenmektedir (Cabrera, 2017, s. 150). Dolayısıyla, Ortadoğu'da şehirlerin ruhu üzerine yapılan çağdaş görsel sanat çeşitlilik gösterir.

Fakat çağdaş sanat öncesinde, Ortadoğu'da modern sanatın kurumsallaşması ve yaygınlaşmasında Claude Monet'nin öğrencisi olan Mohammed Naji'yi (1888-1956), Raghed Ayad'ın (1882-1982) gündelik yaşamı betimlediği resimlerini veya Mahmoud Mokhtar'ın (1891-1934) heykellerini hatırlamak gerekir. Ayrıca, Kahire’de 1908 yılında kurulan Güzel Sanatlar Okulu'nu ve Irak'ta 1939'da kurulan Sanat Enstitüsü'nü dikkate almak gerekir. Nasıl çağdaş sanatın gelişiminde modern sanatın payı büyükse, modern sanatın oluşumunda klasik/ akademik sanatın payı da o kadar büyük olmaktadır (Farjam, 2009, s. 10). Bu bağlamda, Ortadoğu coğrafyasında kadim uygarlıklar ve sanatlarından çok esinlenilmiştir.

Günümüzde genç sanatçıların çağdaş eserlerini değerlendirirken, şehirler üzerine tartışmadan önce ülkeler ve sınır güvenliği üzerine eserler verildiğini söylemek doğru olacaktır. Sykes-Picot Antlaşması'ndan günümüze kadar Ortadoğu söz konusu olduğunda 
şehir ve ülke arasında ayrımların muğlaklaştığı gerçeği yadsınamaz. David Fromkin'in tüm barışlara son veren barış olarak adlandırdığı Birinci Dünya Savaşı sonrası politik ve coğrafi düzen değişimleri görece bölgeyi etkilemeye günümüzde dahi devam etmektedir. Dolayısıyla, Mona Hatoum ve Oraib Toukan öncü-çağdaşların eserleri gerek şehir gerekse ülke sınırları açısından rahatlıkla yorumlanabilir.

Bu bağlamda ilk olarak, Filistinli sanatçı Mona Hatoum’un (1954) eserlerinden bahsetmek gerekir. Örneğin, sanatçı “Şimdiki Zaman” (1996) başlıklı enstalasyonunda sabunlardan bir zemin oluşturur. Zeminde sabunları iterek oluşturulan yeni bir dünya haritası resmedilmektedir. Alistair Hicks'e göre Hatoum'un sabunu Kudüs zeytininden yapılma geleneksel bir Filistin ürünüdür ve tarafsız bir izleyici bunu bir zeytin dalı olarak düşünebilir (Hicks, 2015, s.76). Fakat Hotoum'un kavgacı zekâsının bir yansıması olarak "Yabancı Beden" (1994) ve "Derin Boğaz" (1996) gibi eserlerine bakıldığı zaman kendi bedenini harita gibi kullandığı görülür. Sanatçı, "Harita" (1999) adlı eserindeyse cam bilyelerden oluşturduğu kıtaların değişimini vurgulamaktadır. Uluslararası ölçekte yaşanan sorunların Kenneth Waltz tarafından geliştirilen neo-realist bağlamda (Waltz, 1959, s.12-15.) bireylere olan etkisinin tartışılması sanatçı için önemlidir. Böylece, beden dilinin politikayla özdeşlemesi insanın kendi sınırlarını aşıp aşamadığ 1 sorusunu gündeme getirir.

Filistinli sanatçı Oraib Toukan (1977) "Daha Yeni Ortadoğu” başlıklı eserinde mıknatıslı bir yap-boz mekanizması oluşturur. Sanatçının ailesi Filistinli olmakla birlikte, kendisi ABD'de doğmuş ve halen Ürdün'de yaşamaktadır. Bir tür enstalasyonu çağrıştıran eserde, Ortadoğu ülkelerinin her biri on yedi adet beyaz köpükten oluşan mıknatısla birleştirilmiş. İzleyiciler, bu mıknatıslı parçaları istedikleri gibi değiştirip yeni bir Ortadoğu inşa edebiliyorlar (Hicks, op.cit., s.80). Sykes-Picot Antlaşması'ndan günümüze inşa edilmenin tamamlanmayan bir süreç haline dönüştüğü Ortadoğu bütünü eserde betimlenmeye çalışılır. Esere dikkatlice bakıldığında, kaba inşaatı bitmiş, bir türlü çatısı örülemeyen ve her katın yanına ve üstüne yeni katlar yapılmak üzere demir filizlerin çıkıldığı mahalleler akla gelmektedir. Toukan, öte yandan Ortadoğu'da olup bitenlere seyirci kalmamak üzerinden, seyirci ve sanatçı arasında özne-nesne ilişkisini sorgulamayı da ihmal etmez. İnsan veya devlet eliyle değişim mantığı bir tarafa, diğer taraftan mıknatıslar sınırların gelip-geçici talihsizliğini vurgularken ülkelerin birbirlerine olan ayrılamaz bağını da vurgulamaktadır.

Marwan Rechmaori (1964) ise kauçuk malzemeden ürettiği halı görünümlü eseriyle Beyrut'un deprem, yangın ve savaşlarla geldiği noktayı anlatır. "Kauçuk Beyrut” (20042008) sanatçının değimiyle coğrafi ve kültürel farklılıkların sınır oluşturmadığı bir şehrin yalnızlığını sokak ve meydanlarla gözler önüne sermektedir. Günümüzde şehrin kaderini 
altüst eden çeşitli yangın ve patlamaların yaşanması kent ile yaşam arasındaki ilişkinin sadece bulanık olmasına değil aynı zamanda uçucu olmasına, başka bir anlatımla aniden yok olmasina neden olmaktadır.

Rechmaori’nin “Yaşam Binası” (2001-2008) adlı eserindeyse Beyrut'ta uzun yıllar kullanılmayı bekleyen gökdeleni anlatır. 1970'lerde tasarlanan bu binanın metruk haliyle savaş zamanı sokakları gözetleyen keskin nişancıların merkezi olması önemlidir. Pierre Nora'nın deyimiyle kent mekanlarının (Nora, 1986, s. 655) toplum hafizasındaki edindikleri yerin niteliği söz konusu bir Ortadoğu şehriyse dikkat çekicidir. Feyruz'un Beyrut'undan bu yana kentin mekanlarının şiddet olaylarıyla hafızalara kazınması sanatçının enstalasyonuyla gözler önüne serilmektedir. Lübnan'da yaşanan şiddeti kent mekanları üzerinden anıtsallaştırırken aslında sanatçı ikonoklast bir yorum sergilemektedir.

Beyrut'u konu alan bir başka çağdaş sanatçı Walid Raad (1967) ise tek kanallı videosu “Sweet Talk: Comission” (1994-1997) ile Beyrut'un yakın tarihini gerçekle kurgu arasında bir ilişki olarak tanımlar. Walter Benjamin'in en çok etkilendiği fotoğraf sanatçısı Eugène Atget gibi (Benjamin, 2019, s.114) şehrin dilini anlatmaya özen gösteren Raad, şehrin mekanlarını izleyiciye yakınlaştırmaya çalışır. İletişim araçlarının iletişimsizliği perçinlediği bir düzlemde şehir belgesellerinin anımsamaktan çok unutturmayı amaçladığının altını çizer. Bu nedenle, Baudrillard'ın simülasyon kuramından hareketle şehrin bozulan gerçekliğine de dikkat çeker (Baudrillard, 1994, s.16-17). Birden fazla gerçekliğin arasında hakikatini yitirmeye başlayan Beyrut, giderek daha da çoğalan yanılsamaların kurbanına dönüşmektedir.

Lübnan gibi Mısır da son yıllarda şiddetin ulusal ve uluslararası dönüşümlerine tanıklık etmektedir. Bu noktada çağdaş bir sanatçı olup, eski uygarlıklardan etkilenen genç sanatçı Alaa Awaad değinmek gerekir. Mısır kökenli sanatçı Alaa Awaad (1981) Tahrir Meydanı gibi Kahire'nin çeşitli meydan ve sokaklarında Mısır hiyerogliflerinin retrospektifini oluştururcasına duvar resimleri yapmaktadır. Bansky'den ilham alan Awaad, Kahire duvarlarını birer açık hava galerisine dönüştürmektedir. Sanatçı, Eski Mısır uygarlığını betimlerken politik ve sosyal konulara değinmeyi ihmal etmez. Awaad'ın asıl üzerinde durmak istediği konu, kent kalıntılarından geçmişle bugünü birleştirici simgeler yaratmaktır. Kent içinde yaşanan olayların, bir başka anlatımla şehrin dilinin, Fernand Braudel'in tabiriyle "la longue durée" (Braudel, 2013, s.14-16) yani çağlara eşdeğer bir uzun zaman zarfinın parçası haline getirmek sanatçının temel işlevi olur.

Sadece Lübnan veya Mısır ile sınırlı kalmak yerine bir başka Ortadoğu ülkesi Irak'a ve şehirlerine de değinmek gerekir. Bu bağlamda Irak doğumlu Ahmed Alsoudani’nin 
(1975) eserlerine başvurmak gerekir. Latin Amerikalı sanatçı Fernando Botero'nun grotesk tekniğini kullanarak Ahmed Alsoudani, “Bağdat” (2008) adlı eser serisinde Pablo Picasso'nun “Guernica” adlı eserini ironik bir üslupla Ortadoğu'ya yorumlar (Lévy, 2013, s.19). Renklerin ve cisimlerin birbirine karıştığ çalışmada toplumun alt üst oluşu anlatılmaktadır. Körfez Savaşı ve Amerikan İşgali sonrasında İran da dahil olmak üzere farklı devletler için bir güç mücadelesinin parçası haline dönüşen Irak’ta özellikle Bağdat'ın parçalanması söz konusudur. Şehrin ülke içinde yaşanan olayların “mikrokozmos”u haline dönüşmesi Alsoudani tarafından iki savaş arası dönemde İspanya'nın yaşadıklarına eş değer bir kırılmayla eş değer kabul edilmektedir.

Tekil bağlamında şehirleri betimleyen çağdaş sanatçılardan farklı olarak Ebtisam Abdulaziz ise bireyleri ve Ortadoğu sokaklarını yorumlamaya çalışır. Abdulaziz, "Otobiyografi”" (2003) adlı performansında kavramsal sanata bir gönderme yaparak üzerinde barkodlardan oluşan vücudunu saran siyah bir çarşafla görünür. Coğrafi varlıkları matematiksel şekillere dönüştüren sanatçı, savaş ve ekonominin Ortadoğu'daki etkisini betimlemektedir (ibid, s.83). Performansın en ilginç noktası, kentin farklı noktalarında, bireysel ve toplumsal kayboluşu, bir başka anlatımla yersiz/yurtsuzlaşmayı dile getiriyor olmasıdır. Böylelikle, Jürgen Habermas'ın kamusallık yorumuna tezat bir biçimde (Habermas, 2005, s.57-58), etnik çatışmaların devam ettiği bir coğrafyada beden ve mekân kimliği üzerinden bir performatif sanat örneğini gözlemleriz. Böylece, seyirci sanat eserini bir parçası gibi hareket etmeye başlar ve kent mekanlarıyla iletişim kurar.

Suriyeli sanatçı Diana al-Hadid (1981) “Şehirler” adlı heykellerinde, çocukluğundan özlemini duyduğu şehirleri ve insanları sıvılaştırarak bellek yitimini kayda geçirmeye çalışıyor. Ahşap, alçı ve balmumunu kullandığı heykel ve yerleştirmeleri, jeolojik ve ekolojik anlamda hasar görmüş Ortadoğu şehirlerinde antroposen olgusunu inceler. Nicolas Bourriaud'nun iletişimsel estetik kavramından (Bourriaud, 1998, s.11) yola çıkarak sanatçı, insan ve insan-olmayan şeyler arasındaki hiyerarşik ilişkiyi ortaya çıkarmaya çalışır. Ortadoğu gibi hasar görmüş bir coğrafyada, yaşam ve cansızlık arasındaki ayrımlar irdelenmeye çalışılır. Irkçılık, sömürgecilik vb. süreçlerin yarattığı bio-iktidarın yeni oluşumları, sanatçının enstalasyonlarında gözlenmektedir.

\section{Sonuç Yerine}

Çalışma boyunca farkında olmadan odaklanılan ve görece daha çok örneğini bulabildiğimiz birincil sorunsal ülke ve şehir ilişkisi olurken, ikincil sorunsal kent ve insan arasındaki ilişki oldu. Amacımız, şehrin dilinin salt kültürle değil aynı zamanda hakiki ve/ 
veya gerçek kültürlerin çizdiği sınırlarla oluştuğunu gösterebilmektir. Üstelik söz konusu Ortadoğu olunca adına ister kültür, isterse sınır diyelim ortaya çıkan kargaşanın bizzat şiddeti beslediğini unutmamak gerekir. Çağdaş sanatçılar da kendi coğrafyalarında olup bitenleri gerek kendilerinin gerekse şehirlerinin kimliğinden oluşan yeni bir dille aktarmaya çalışmaktadırlar. Bu noktada önemli olan, sanatsal duyarlılığın politik olandan bağımsız düşünülemez olmasına ve farkındalık yaratmak için şiddeti "estetik" açıdan eleştirmek gerektiğine dair yanttlar aramaktır.

Ülke sınırlarının değişkenliği bağlamında yaşanan kaotik ortamın kent dokusuna yansıması değerlendirilmektedir. Mona Hatoum'un kavramsal sanat çalışması, Oraib Toukan'ın performatif sanat örneği, Alaa Awaad'ın yarı hieyeroglif duvar resimleri, Walid Raad'ın video gösterimi, Marwan Rechmaouri'nin farklı enstalasyonları kentlerin Ortadoğu tarihiyle sınavını resmetmektedir. Ebtisam Abdulaziz'in performatif sanat alanındaki çalışmaları ve Diana alHadid'in yerleştirmeleri Ortadoğu'da kent ve birey ilişkisinin "antroposen” bağlamında farklı teknikler üzerinden kavramsallaştırmıştır.

Bir başka anlatımla, Fernand Braudel'in tarihi süreçleri aktarması gibi Alaa Awaad sanat eserlerine kentin tarihini aktarırken, Marwan Rechmaouri eserlerinde Ortadoğu şehirlerinin mekânsal hafıza yaratmasını betimlemektedir. Fakat savaş ile barışın ve kültürlerarası çatışmanın kol gezdiği bir coğrafyada Ebtisam Abdulaziz'in de yorumladığı gibi Jürgen Habermas tarafindan öncellenen bir kamusallıktan bahsetmek için artık geç olduğu aşikardır. Bölgede hakikatle ilgili bağların kopmasına dikkat çeken çağdaş sanatçı Walid Raad'ın, Jean Baudrillard üzerinden eserlerine yorum kattığını, bununla birlikte, Diana al-Hadid ve benzer çağdaşların anlatmaya çalıştı̆̆ gibi iletişimsel bir estetiğin Ortadoğu şehirlerinde varlık sürdürdüğünü de unutmamak gerekir.

Özetle, Ortadoğu'daki sarmalda sanat ve şehirde yaşamaya dair, Shakespeare'in "Venedik Taciri" adlı eserinden bir alıntı yapmak olan biteni anlamaya yardımcı olabilir. Shylock karakteri "Bizi bıçakladığında kanımız akmaz mı?" sorusuyla günümüzde bile devam eden Ortadoğu' daki kaos ve kafa karışıklığını özetleyecek bir empati yoksunluğuna değinir. Çağdaş sanatçıların, Ortadoğu'daki şehir betimlemeleriyle göstermeye çalıştıkları da benzer bir kaos ve empati sorunudur aslinda. 


\section{Kaynakça / References}

Baudrillard J. (1994). La Pensée Radicale [The Radical Thought.]. Paris, France: Editions Sens \& Tonka.

Benjamin W. (2019). Fotoğraf Yazıları [On Photography] (B. Halaç ve T. Turan, Çev.). İstanbul, Türkiye: Kolektif Kitap.

Bourriaud N. (1998). Esthétique Relationelle [The Relational Aesthetics]. Dijon, France: Les Presses du Réel. Braudel F. (2013). Ecrits sur l'histoire [Writings on History]. Paris, France: Editions Flammarion.

Burke, P. (2006). Kültür Tarihi [What is Cultural History?] (M. Tunçay, Çev.). İstanbul, Türkiye: İstanbul Bilgi Üniversitesi Yayınları.

Cabrera, H. (2017). Íslam ve Çăgdaş Sanat [Islam and Contemporary Art] (I. Aybek, Trans.). Ankara, Türkiye: Hece Yayınları.

Childe G. (2006). Tarihte Neler Oldu? [What Happened in History?] (A. Şenel ve M. Tunçay, Çev.). İstanbul, Türkiye: Kırmızı Yayınları.

Farjam L. (2009). Look Again. Unveiled: New Art form the Middle East, London, United Kingdom: Booth-Clibborn.

Goody J. (2014). Tarih Hırsızlı̆̆l [The Theft of History] (G. Güven, Çev.). İstanbul, Türkiye: Türkiye İş Bankası Yayınları.

Habermas J. (2005). Kamusallı̆̆ın Yapısal Dönüşümü [Transformation of Publicness] (T. Bora ve M. Sancar, Çev.). İstanbul: Türkiye, İletişim Yayınları.

Halliday F. (2008). Ortadoğu Hakkında 100 Mit [100 Myths About the Middle East] (C. Cemgil, Çev.). İstanbul, Türkiye: İstanbul Bilgi Üniversitesi Yayınları.

Hicks A. (2015). Küresel Sanat Pusulası: 21. Yüzyıl Sanatında Yeni Yönelimler [The Global Art Compass: New Directions in 21th Century Art] (Şendil, Haydaroğlu, Evren, Çev.). İstanbul, Türkiye: Yapı Kredi Yayınları.

Hobson J. (2008). Batı Medeniyetinin Doğulu Kökenleri [The Eastern Origins of Western Civilization] (E. Ermert, Çev.). İstanbul, Türkiye: Yapı Kredi Yayınları.

Kardeş E. (2019). Yönsüzleşmiş Savaşlar: Politik Felsefenin Bir Sinır Meselesi olarak Savaşa Dair [Disoriented Wars: The Wars as A Limit Problem of Political Philosophy]. İstanbul, Türkiye: Pinhan Yayınc1lık.

Lefevbre H. (1972). Le Droit à la Ville [The Right to the City]. Paris, France: Editions Anthropos.

Lévy B. H. (2013). Les Aventures de la Vérité [The Adventures of Truth]. Paris, France: Grasset.

Nora P. (1986). Les Lieux de Mémoire [The Places of Memory]. Paris, France: Gallimard.

Said E. (2016). İktidar, Siyaset ve Kültür [Power, Politics, and Culture]. (S. Özer, Çev.), İstanbul, Türkiye: Hece Yayınlar1.

Waltz K. (1959). Man, the State, and War: a Theoretical Analysis. New York, USA: Columbia University Press. 
